\title{
PAHAM KENABIAN MIRZA GHULAM AHMAD MENURUT PERSPEKTIF JAMAAH AHMADIYAH LAHORE (GAI) DI INDONESIA
}

\section{PROPHETY OF MIRZA GHULAM AHMAD ACCORDING TO THE PERSPECTIVE OF THE JAMAAH AHMADIYAH LAHORE (GAI) IN INDONESIA}

\author{
Sahid Al-Marwan ${ }^{1}$ \\ IAIN Syekh Nurjati Cirebon \\ Hajam $^{2}$ \\ IAIN Syekh Nurjati Cirebon \\ Naila Farah ${ }^{3}$ \\ IAIN Syekh Nurjati Cirebon
}

\author{
sahidalmarwan@gmail.com
}

hajam@syekhnurjati.ac.id

nailafarah18@gmail.com

\begin{abstract}
ABSTRAK: Ketegangan yang terjadi dalam menyikapi Ahmadiyah selama ini sesungguhnya dipicu oleh kesalahpahaman terhadap penggunaan istilah "nabi" yang digunakan Ahmadiyah dalam konteks tasawuf, sebagaimana para wali dan para sufi juga menggunakannya ketika pemimpin kharismatik aslinya (Ghulam) dijadikan titik fokus penghormatan dan cinta yang luar biasa, dari kacamata tasawuf, pola yang mirip dengan tarekat, karena menekankan bai'at dalam keanggotaannya. Penelitian ini bertujuan untuk (1) Menjelaskan ajaran Ahmadiyah tentang Kenabian. Mirza Ghulam Ahmad (2) Memahami ajaran Ahmadiyah tidak menyimpang dari Islam yang dibawa Muhammad SAW (3) Mengetahui kebenaran pemahaman Mirza Ghulam Ahmad yang atas klaimnya mendapatkan Wahyu. Penelitian ini merupakan penelitian kualitatif dengan mengunakan pendekatan penelitian kepustakaan (library research). Sumber data berasal dari data primer dan sekunder, data primer yaitu sumber tertulis primer dan sumber tertulis dengan alat mekanik menyaksikan peristiwa yang diceritakan (sumber autentik dan sumber langsung). Data sekunder berupa sumber-sumber yang berkaitan dengan peneltian ini. Teknik pengumpulan data yang digunakan yaitu studi pustaka dan studi dokumentasi. Teknik analisis data menggunakan teknik content analysis, reduksi data dan penyajian data. Hasil penelitian menunjukkan bahwa pandangan jamaah Ahmadiyah Lahore (GAI) di Indonesia secara umum memusatkan pada pengalaman Mirza Ghulam.
\end{abstract}

Kata Kunci: Makna Kenabian, Ahmadiyah, Mirza Ghulam, Lahore, GAl.

ABSTRACT: The tension that has occurred in dealing with Ahmadiyah so far has actually been triggered by a misunderstanding of the use of the term "prophet" which is used by Ahmadiyah in the context of Sufism, as the saints and Sufis also use it when the original charismatic leader (Ghulam) is used as a focal point of great respect and love, from the point of view of Sufism, the pattern is similar to that of the tarekat, because it emphasizes the bai'at in its membership. This study aims to (1) explain the Ahmadiyah teachings about Prophethood. Mirza Ghulam Ahmad (2) Understanding Ahmadiyah teachings that do not deviate from Islam brought by Muhammad SAW (3) Knowing the truth of Mirza Ghulam Ahmad's understanding who claims to have received revelation. This research is a qualitative research using a library research approach. Sources of data come from primary and secondary data, primary data, namely primary written sources and written sources using mechanical devices to witness the events being told (authentic sources and direct sources). Secondary data in the form of sources related to this research. Data collection techniques used are literature study and documentation study. The data analysis technique uses content analysis, data reduction and data 
presentation techniques. The results show that the views of the Lahore Ahmadiyah congregation (GAl) in Indonesia generally focus on Mirza Ghulam's experience.

Keyword: Propethic Meaning, Ahmadiyah, Mirza Ghulam, Lahore, GAl.

\section{A. PENDAHULUAN}

Masalah kenabian dalam Islam maupun agama lainnya, tidak hanya bersifat fundamental bagi para penganutnya, tetapi juga menimbulkan penafsiran yang rawan menimbulkan konflik horizontal di dalam kelompok-kelompok keagamaan agama-agama besar yang ada. ${ }^{1}$ Hingga sekarang, khususnya di dalam dunia Islam, masalah tersebut tetap dianggap belum tuntas dan kerap menjadi perselisihan internal. Sebab kenabian merupakan pokok inti keimanan, manakala terjadi distorsi atau penyimpangan pemahaman mengenainya oleh individu maupun kelompok, konsekuensi yang dapat diterimanyapun cukup serius. Salah satu contoh perbedaan pemahaman dalam Islam ialah tentang Nabi Muhammad saw sebagai penutup para Nabi dan Rasul. Nabi dan Rasul merupakan hal sentral dalam sistem kepercayaan Islam dan terkait erat dengan semangat ajaran Islam. ${ }^{2}$

Telah umum diketahui, jika Nabi sering didefinisikan dengan laki-laki balig, berakal, berbudi pekerti baik dan diturunkan kepadanya wahyu. Jika wahyunya mengandung hukum-hukum baru yang belum terdapat dalam syariat sebelumnya, maka dia dinamakan sebagai Nabi yang membawa syariat baru. Sementara Ahmadiyah jika mereka tidak membawa syariat baru, maka dia dinamakan Nabi pembantu. ${ }^{3}$ Keanekaragaman pemahaman terhadap ajaran-ajaran Islam inilah yang kadang-kadang disebabkan oleh perbedaan dalam memahami dan menginterpretasikan al-Qur'an yang dapat melahirkan berbagai paham dan aliran keagamaan sebagaimana yang dialami Ahmadiyah. ${ }^{4}$

Bukan saja antar Jamaah Ahmadiyah sendiri, tetapi dengan kelompok keagamaan mainstream, yang dalam beberapa hal yang membedakannya adalah penafsiran mengenai pemahaman tentang kenabian, konsep tentang wahyu, dan kedatangan Nabi Isa yang

\footnotetext{
${ }^{1}$ Eni Zulaiha, "Fenomena Nabi dan Kenabian dalam Perspektif AlQuran," Al Bayan: Jurnal Studi AlQur'an dan Tafsir 1, no. 2 (2016): 149-64.

${ }^{2}$ Nurcholis Majid, Kontekstualisasi Doktrin Islam dalam Sejarah, ed. oleh Budy Munawar Rahman, 2 ed. (Jakarta: Paramadina, 1995).

${ }^{3}$ M Ahmad Nuruddin, "Falsafah Kenabian, Jemaat Ahmadiyah Indonesia" (Bogor, 1999).

${ }^{4}$ Ahmad Fidyani Syaifuddin, Konflik dan Integrasi Perbedaan Faham dalam Agama Islam (Jakarta: Rajawali, 1986).
} 
kedua $^{5}$ karena hal tersebut terdokumentasikan dalam al-Qur'an, untuk kebanyakan umat Islam di Indonesia, bertentangan dengan doktrin Muhammad saw sebagai Khotamil Anbiya yang merupakan hal yang final. Sementara, Mirza Ghulam Ahmad menegaskan diri sosok messiah yang mendapatkan wahyu, tampaknya dianggap keliru meskipun sebuah doktrin yang sebetulnya terdapat pula di dalam agama lain. ${ }^{6}$

Sebenarnya, kenabian yang menimbulkan kontroversi tersebut, telah dijernihkan dengan pernyataan "Tidak ada Nabi sesudah Nabi Suci Muhammad saw, baik Nabi lama maupun Nabi baru", sambil merujuk sabda Nabi saw "Lâ nabiyya ba'dî". Oleh karena itu, jika orang mau memperhatikan fakta ini, maka kontroversi klaim kenabian Hazrat Mirza Ghulam Ahmad seharusnya telah berakhir. ${ }^{7}$

Pada dasarnya, tuduhan bahwa Mirza Ghulam Ahmad mengaku sebagai Nabi tidaklah sesuai dengan pengakuan Mirza Ghulam Ahmad sendiri, tetapi hanya merupakan kesalah pahaman saja yang lahir ketika internal umat Islam pada masanya, baik di India maupun luar India, berada pada kondisi yang memprihatinkan dan mengalami kemunduran, termasuk dalam bidang keagamaan. Dalam konteks ini, Ahmadiyah lahir sebagai protes atas kemorosotan Islam pada saat itu yang sebagian besar di bawah cengkraman kolonialisme negara-negara Barat. $^{8}$

Sangat mungkin keberadaan Jamaah Ahmadiyah di Indonesia pada fase awal perkembangannya berangsur-angsur dapat diterima di Indonesia, hingga diakui secara sah mendapatkan badan Hukum berdasarkan Surat Keputusan Menkeh RI No.JA5/23/13 tanggal 13 Maret 1952 (Tambahan Berita Negara RI tanggal 31 Maret 1953 No.26), serta terdaftar di Depag RI tanggal 2 Maret 1970 dengan No.046/J/1970 dan di Depsos dengan No. D-V/70 tanggal 15 Mei $1970 .^{9}$

Tetapi, tidak demikian dalam perkembangan selanjutnya, pemerintah Indonesia mengeluarkan fatwa MUI Tahun 2005 dan Tahun 2007, yang masing-masing membahas dan menyatakan bahwa Ahmadiyah adalah ajaran sesat. Keputusan bersama kementerian mengeluarkan komunitas Muslim Ahmadiyah untuk berdakwah dengan hukuman lima

\footnotetext{
${ }^{5}$ Syarif Ahmad Lubis, Jemaat Ahmadiyah: Sebuah Pengantar (Parung: JAI, 1994).

${ }^{6}$ Barsihannor, Haruskah Membenci Ahmadiyah (Yogyakarta: Kota Kembang, 2009).

${ }^{7}$ Mulyono, "Ahmadiyah Pasca Fatwa," ahmadiyah.org, 2012, https://ahmadiyah.org/ahmadiyah-pascafatwa/.

${ }^{8}$ Ajid Thohir dan Ading Kusdiana, Islam di Asia Selatan, Melacak Perkembangan Sosial, Politik Islam di India, Pakistan dan Bangladesh (Bandung: Humaniora, 2006).

${ }^{9}$ Barsihannor, Haruskah Membenci Ahmadiyah.
} 
tahun penjara atas penodaan agama. ${ }^{10}$ Meski fatwa-fatwa MUI memang tidak memiliki otoritas hukum yang mengikat, namun fatwa mereka sanggup memobilisasi opini publik, sedangkan pemerintah sendiri kerap menganggapnya sebagai pertimbangan penting dalam mengambil keputusan.

Mubaligh Besar Ahmadiyah Lahore pernah mengklarifikasi fatwa tersebut kepada MUI agar tidak menimbulkan salah tafsir. Di sana diketahui jika pernyataan ajaran sesat yang dikeluarkan MUI ditujukan kepada JAI. "Hanya saja sampai sekarang fatwa tersebut tak juga direvisi", namun pengakuan semacam inipun ditolak oleh kebanyakan umat Islam. ${ }^{11}$ Bagaimanapun, baik Ahmadiyah Indonesia cabang Lahore (GAI), maupun cabang Qodian (JAI), telah menjadi kecenderungan untuk dilihat sebagai gerakan sempalan $^{12}$ baik pandangan Ahmadiyah Lahore, Mirza Ghulam Ahmad adalah mujaddid (pembaharu) dan bukan Nabi sebagaimana yang diyakini oleh Jemaat Ahmadiyah Qadian ${ }^{13}$ Mirza adalah Al Imam Mahdi yang turun setelah Muhammad saw tetapi tidak membawa syariah baru, juga tidak satu ayat pun di al-Qur'an yang dikurangi atau tambahkan tetap mempercayai Nabi Muhammad saw sebagai khatam al-nabiyyin, yakni sebagai Nabi yang paling sempurna dan Nabi terakhir pembawa syariat. ${ }^{14}$

Ketegangan yang terjadi dalam menyikapi Ahmadiyah selama ini sesungguhnya dipicu oleh kesalahpahaman terhadap penggunaan istilah "Nabi" yang terjadi pada MUI, terhadap penggunaan kata "Nabi" yang digunakan Ahmadiyah dalam konteks tasawuf, sebagaimana para wali dan para sufi juga menggunakannya ketika pemimpin kharismatik aslinya (Ghulam) dijadikan titik fokus penghormatan dan cinta yang luar biasa, ${ }^{15}$ dari kacamata tasawuf, pola ini mirip dengan tarekat, karena menekankan bai'at dalam keanggotaannya. ${ }^{16}$

\footnotetext{
${ }^{10}$ Amin Mudzakkir, "Minoritasi Ahmadiyah di Indonesia," Masyarakat Indonesia: Jurnal Ilmu-Ilmu Sosial Indonesia 37, no. 2 (2011): 1-24.

${ }^{11}$ Maman Sutirman, Kunto Sofianto, dan Agus Nero Sofyan, "Respons Jemaat Ahmadiyah Indonesia terhadap Fatwa Majelis Ulama Indonesia serta Kajian dari Lembaga Penelitian dan Pengkajian Islam," Sosio Humanika 12, no. 2 (2019): 105-20.

${ }^{12}$ Martin van Bruinessen, Rakyat Kecil, Islam, dan Politik (Yogyakarta: Gading, 2013). Terutama sebagai ancaman terhadap stabilitas keamanan dan untuk segera melarangnya. Karena itu; sulit membedakan gerakan sempalan dengan gerakan terlarang atau gerakan oposisi politik oleh pemerintah.

${ }^{13}$ M. Amin Djamaluddin, Ahmadiyah dan Pembajakan Al-Qur'an (Jakarta: LIPI, 2003).

${ }^{14}$ Ida Novianti, "Kenabian Mirza Ghulam Ahmad" (Purwokerto: STAIN Purwokerto Press, 2006).

${ }^{15}$ Bruinessen, Rakyat Kecil, Islam, dan Politik.

${ }^{16}$ Agus Riyadi, "Tarekat sebagai Organisasi Tasawuf (Melacak Peran Tarekat dalam Perkembangan

Dakwah Islamiyah)," Jurnal at-Taqaddum 6, no. 2 (2014): 359-85.
} 
Sebagaimana yang dicatat John L. Esposito inti pemikiran Ahmadiyah adalah profetologi, yang inspirasinya berasal dari sufi besar Abad Pertengahan, Muhyîdin ibn alArabi (1165-1240) mengemukakan dalil tentang suksesi berkesinambungan "Nabi-Nabi tak bersyari'at" sepeninggal Nabi Muhammad saw. Dengan menyebut pendirinya berstatus jurus selamat dan Nabi, gerakan Ahmadiyah membangkitkan pertentangan sengit dari kaum muslim Sunni. Ia dituduh telah mengingkari dogma bahwa Muhammad saw merupakan Nabi terakhir. ${ }^{17}$

Sayangnya, keberadaan Ahmadiyah di Indonesia mulai dihargai hanya baru oleh sebagaian kalangan moderat, dan klaim ajaran sesat yang telah lama melekat karena menempatkan status Mirza Gulam Ahmad sebagai Nabi, dan pengukuhan maksud pengagungan pada Mirza Gulam Ahmad tetap belum dipahami oleh sebagian besar umat Islam di indonesia. Agar masalah tersebut tidak terus berlanjut, tentulah tidak hanya perlu pendekatan secara yuridis, sebagaimana mestinya melindungi keyakinannya dan nasib keselamatan jiwanya, tetapi juga di butuhkan kegiatan ilmiah yang mengkaji hal tersebut. Oleh sebab itu, perspektif kenabian yang dipahami Ahmadiyah di Indonesia perlu mendapat perhatian khusus secara akademis.

Oleh karena itu, penelitian ini berusaha menjelaskan lenabian dari kacamata Ahmadiyah Indonesia. Penulis tertarik untuk menelitinya karena mengingat paham GAI tentang kenabian Mirza Ghulam Ahmad pada dasarnya tidak bertentangan dengan syariat. Selain itu juga, studi tentang jamaah Ahmadiyah di Indonesia yang telah banyak dilakukan, kebanyakan berkutat pada dakwah dan kekerasan terhadap Ahmadiyah. Sementara, studi yang memperjelas pandangan jamaat Ahmadiyah di Indonesia dalam hal kenabian Mirza Ghulam Ahmad yang begitu berbeda sangatlah sedikit, maka penting sekali untuk diteliti. Keberatan pengakuan sebagai Nabi sesungguhnya lebih disebabkan salah paham terhadap istilah yang digunakan. Mirza Ghulam Ahmad menggunakan istilah itu dalam frame sufi (karena ia memang seorang sufi), sementara para penolak memahami menurut istilah syar'i.

\section{B. METODE PENELITIAN}

Penelitian yang dilakukan penulis adalah termasuk jenis penelitian pustaka (library research), yaitu serangkaian kegiatan penelitian yang berkenaan dengan proses

\footnotetext{
${ }^{17}$ Adi Fadli, "Ahmadiyah: Sebuah Titik yang Diabaikan,” Ulumuna 11, no. 2 (2007): 413.
} 
pengumpulan, pembacaan, pencatatan, serta pengolahan bahan dan data penelitian yang berdasarkan sumber pustaka. ${ }^{18}$ Metode yang digunakan dalam penelitian ini yakni metode penelitian kualitatif. Sifat penelitian ini bernarasi induktif yang lebih menekankan hasil riset dari umum ke khusus. Sebagai prosedur penelitian yang menghasilkan data deskriptif berupa kata-kata tertulis atau lisan dari orang atau perilaku yang diamati.

Adapun landasan teori yang digunakan dalam penelitian kenabian Mirza Ghulam Ahmad menurut persfektif Jamaah Ahmadiyah Lahore (GAI) di Indonesia adalah teori Marcea Eliade sebagai berikut: kenabian atau mesianik menurut Eliade, "selalu tertuju kepada suatu realitas atau situasi yang melibatkan eksistensi manusia" dan "sikap terbuka kepada roh dan, akhirnya, kemampuan mendekati yang universal (sacred)". ${ }^{19}$ Dengan menitik beratkan teorinya pada bagaimana manusia mengalami dan memahami The Sacred dalam pelaku agama. The Sacred di sini merupakan sebagai bentuk sinonim bagi transendensi. ${ }^{20}$

\section{HASIL DAN PEMBAHASAN}

\section{Paham Kenabian dalam Ahmadiyah}

Arti Nabi menurut lughat akar katanya adalah naba' artinya 'kabar'. Jadi, orang mendapat kabar gaib atau nubuat, yaitu sesuatu yang diramalkan jauh sebelum suatu kejadian terjadi, dan itu datangnya dari Allah SWT. Dzat Yang Maha Mengetahui segala perkara yang gaib dan ia tidak menzhahirkan kegaiban-Nya, kecuali kepada seorang Utusan-Nya yang Dia ridhoi. ${ }^{21}$ Kondisi fleksibel dari kemunculan al-Mahdi menyebabkan klaim atas otoritas personal ketika kepentingan-kepentingan Islam dianggap terancam. Artinya, wacana al-mahdi ini kapan dan di mana saja dapat muncul jika keadaan umat Islam berada dalam kondisi kritis. ${ }^{22}$

Bab ini akan menjelaskan bagaimana Jamaah Ahmadiyah memahami konsep Kenabian yang diterima Mirza Ghulam Ahmad. Kata "Nabi" yang ada pada Muhammad saw sebagai Nabi yang terakhir membawa syari'at. Namun, tidak kemudian diartikan bahwa Nabi setelah Muhammad saw tidak diturunkan oleh Allah

\footnotetext{
${ }^{18}$ Medika Zed, Metode Penelitan Kepustakaan (Jakarta: Yayasan Obor Indonesia, 2008).

${ }^{19}$ F. W. Dillistone, The Power of Symbol, ed. oleh A. Widyamartaya, 5 ed. (Yogyakarta: Kanisius, 2006).

${ }^{20}$ Peter Connolly, Aneka Pendekatan Studi Agama, ed. oleh Imam Khoiri (Yogyakarta: LKiS, 2011).

${ }^{21}$ H. R. Munirul Islam Yusuf, Bantahan Lengkap (Menjawab Keberatan Atas Beberapa Wahyu di Dalam Tadzkirah) Dan Tabayyun (Penjelasan) (Bogor: Bintang Grafika, 2011).

${ }^{22}$ Barsihannor, Haruskah Membenci Ahmadiyah.
} 
SWT, ${ }^{23}$ pengartian dari kelompok Ahmadiyah dengan cukup amat berbeda dengan yang umumnya umat Islam pahami. Karena seperti yang dicatat Louis J. Hammann Tahun 1876 Mirza Ghulam Ahmad mendapatkan wahyu ketika ia berusia 41 tahun. Bagaimanapun, sampai umur 41 tahun (1876) Mirza Ghulam Ahmad mulai menerima banyak wahyu yang akan membawanya kepada keyakinan/kepastian bahwa di dalam pribadinya telah genap datangnya Mahdi. ${ }^{24}$

Mengaku sabagai mulham (penerima ilham) dan muhaddas (orang yang bercakap-cakap dengan Allah), hal itu terjadi pada Tahun 1835-1880 M. Pada Tahun 1880-1891 M, Mirza Ghulam Ahmad mengaku sebagai mujaddid sampai dengan mengaku dirinya sebagai al-Masih dan al-Mahdi. Hal ini berjarak 11 tahun setelah pengakuannya sebagai al-Masih al-Maud. Pada tahun 1990 Mirza Ghulam Ahmad menyatakan diri sebagai $\mathrm{Nabi}^{25}$ yang diungkapkannya sendiri ke dalam bahasa Urdu dan Arab, yang kemudian dikumpulkan dalam satu buku kompilasi wahyu Mirza Ghulam Ahmad yang dinamakan dengan tazkirah, ${ }^{26}$ disusun oleh Mirza Basyiruddin Mahmud Ahmad sebagai Khalifah Ahmadiyah kedua, tazkirah bagi Ahmadiyah sama sucinya dengan kitab suci al-Qur'an, karena kedua-duanya diklaim sebagai wahyu yang turun dari Allah SWT. ${ }^{27}$

Sementara untuk pandangan Sunni sendiri, sebagaimana Edwin Syarif jelaskan, bahwa di dalam Sunni pintu kenabian setelah Nabi Muhammad saw sudah tertutup. Nabi Muhammad saw adalah Nabi yang terakhir dan tidak ada lagi Nabi setelahnya. Nabi jenis apapun tidak ada dan tertutup setelah Nabi Muhammad saw. Hal itu karena Nabi Muhammad adalah khatamun nabiyyin, bahwa tidak tertutup kemungkinan bila ada seseorang memiliki kemampuan atau mampu mencapai tingkat kenabian. Seperti halnya yang disampaikan oleh al-Ghazali, bahwa seseorang bisa mencapai ilmu laduni. Yaitu kemampuan untuk berhubungan dengan hal-hal yang transenden dan metafisik. ${ }^{28}$

\footnotetext{
${ }^{23}$ Abdhul Halim Mahally, Benarkah Ahmadiyah Sesat (Jakarta: Cahaya Kirana Rajasa, 2006).

${ }^{24}$ Louis J. Hammann, The Ahmadiyya Movement in Islam, ed. oleh M. A. Suryawan (Washington DC: Gettysburg College, 1985).

${ }^{25}$ Asep Burhanudin, Jihad Tanpa Kekerasan (Yogyakarta: LKiS, 2005).

${ }^{26}$ M.A Suryawan, Bukan Sekedar Hitam Putih (Tangerang: Azzahra Publishing, 2006).

${ }^{27}$ Hartono Ahmad Jaiz, Aliran dan Faham Sesat di Indonesia (Jakarta: Pustaka Al-Kautsar, 2008).

${ }^{28}$ Dalam seminar yang digelar oleh Fakultas Aqidah Filsafat Ushuluddin UIN Syarif Hidayatullah Jakarta dengan tema "KONSEP KENABIAN LINTAS ALIRAN: Implementasi Islam Rahmatanlil Alamin dalam Perbedaan," pada Rabu (17/9) https://www.ahlulbaitindonesia.or.id/berita/ index.php/s13-berita/konsepkenabian-sunni-syiah-dan-ahmadiyah/,
} 


\section{Kenabian Menurut GAI}

Ahmadiyah Lahore, di Indonesia dikenal dengan Gerakan Ahmadiyah Indonesia (GAI), berpusat di Yogyakarta, yakni golongan yang mempercayai Mirza Ghulam Ahmad sebagai mujaddid dan tidak menganggapnya sebagai Nabi. Pimpinan organisasinya adalah Pedoman Besar GAI, tanpa otoritas internasional yang membawahinya. ${ }^{29}$ Pandangan GAI dalam mendudukkan Mirza Ghulam Ahmad adalah hanya sebagai mujaddid, muhaddats, mulhim, serta Masih dan Mahdi yang dijanjikan dalam berbagai hadis. "Aku bukan Nabi, tetapi muhaddats, dan Allah bersabda denganku. Aku diutus untuk memperbaharui agama Islam (Din-al-Mustafa $S A W)$, dan sesungguhnya Allah telah mengutus pada permulaan abad ini, dan mengaruniaiku berbagai hidayah-Nya". ${ }^{30}$ Mereka memahami wahyu Allah kepada Mirza Ghulam Ahmad berdasarkan keterangan berikut:

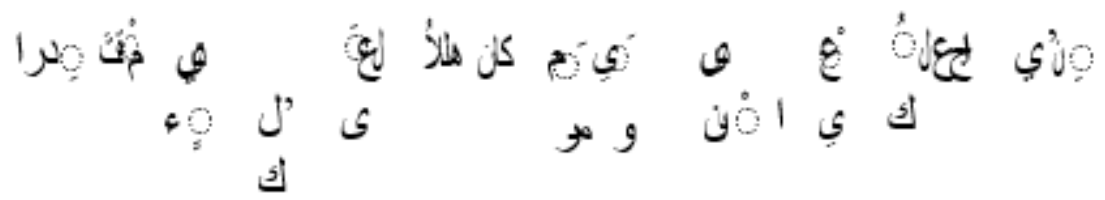

Artinya: "Sesungguhnya Aku telah menjadikan engkau sebagai Isa ibnu Maryam. Sesungguhnya Allah berkuasa atas segala sesuatu." 31

Bagi GAI pengakuan Mirza Ghulam Ahmad dalam tazkiyah di atas, bukanlah sebagai Nabi Shahib Asy Syariah (kenabian yang membawa syariat), dia adalah mujaddid (pembaharu) abad ke-14 H. Akan tetapi ia mempunyai persamaan dengan Nabi dalam hal ia (al-Mahdi) menerima wahyu atau berita samawi (langit). ${ }^{32}$ Bahwa Mirza Ghulam Ahmad dinobatkan sebagai sosok pembimbing mereka yang dinantikannya karena oleh adanya pengukuhan Mirza Ghulam Ahmad sendiri.

\footnotetext{
${ }^{29}$ Iskandar Zulkarnain, Gerakan Ahmadiyah di Indonesia (Yogyakarta: LKiS, 2005).

${ }^{30}$ Amir Aziz Al-Azhari, Pangkal Perpecahan Ahmadiyah, ed. oleh Yatimin A.S (Jakarta: Darul Kutubil Islamiyah, 2016).

${ }^{31}$ Aina Kamalat-e-Islam, hal. 442-443; Tadzkirah hal. 219, Edisi 1969

${ }^{32}$ Oleh sebab itu dalam akidah Ahmadiyah Lahore secara tegas menyatakan bahwa percaya kepada Ghulam Ahmad sebagai al-Mahdi dan al-Masih, bukanlah termasuk rukun iman, maka orang yang mengikarinya tidak dapat dikatakan kafir. A. Fajar Kurnia, Teologi Kenabian Ahmadiyah (Jakarta: Wahana Semesta Intermedia, 2008).
} 


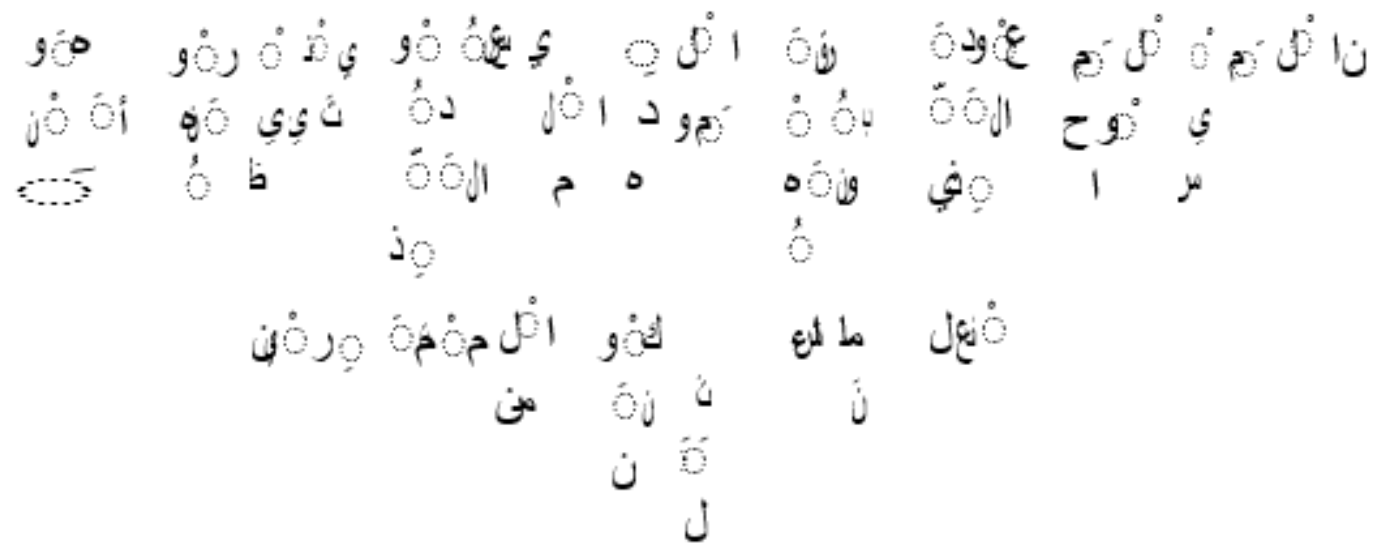

Artinya: Sesungguhnya Al-Masihil Mau'ud yang ditunggu-tunggu dan dinantinantikan kedatangnnya; dia itu engkaulah orangnya. Kami melakukan apa yang Kami kehendaki. Maka janganlah engkau menjadi (peragu) di antara orangorang yang ragu. ${ }^{33}$

Pengukuhan tersebut bukan bagi GAI, tidaklah semata-mata berdasarkan rekaan belaka sebagaimana pihak yang memusuhinya.

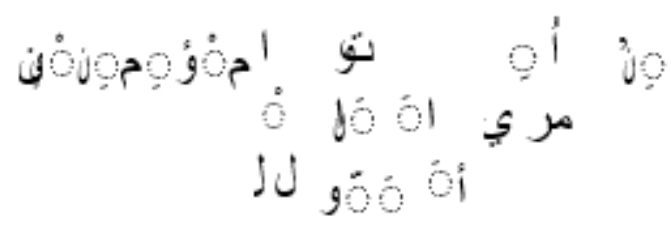

Artinya: Sesungguhnya aku diperintahkan dan aku adalah yang pertama beriman". 34

Bagi mereka bahwasanya Mirza Ghulam Ahmad, seorang mujaddid yang dilakukan tidak datang dari dirinya sendiri, melainkan tugas dari Tuhan yakni rukyat $^{35}$ yang tidak lain merupakan pintu kenabian (ghair syariat) tetap terbuka sampai kiamat. Adapun siapa dan kapan Nabi zhilly itu akan diutus, itu adalah hak prerogatif Allah SWT sendiri. Dalam hal ini, Mirza Ghulam Ahmad orang yang dengan kapasitas ketaatannya pada Allah telah mendapatkan wahyu dari Allah. ${ }^{36}$

Dalam usaha memperjelas maksudnya, GAI mengklasifikasikan kenabian menjadi dua; pertama, Nabi Haqiqi, yaitu Nabi yang ditunjuk langsung oleh Allah SWT dan membawa syariat. Kedua, Nabi Lughawi, yaitu seorang manusia biasa,

\footnotetext{
33 (Atmamul Hujjah (Urdu), hal. 3, Tahun 1896)

${ }^{34}$ Ibid. Hlm. 40

${ }^{35}$ Zulkarnain, Gerakan Ahmadiyah di Indonesia.

${ }^{36}$ RH Munirul Islam Yusuf dan Ekky O. Sabandi, Ahmadiyah Menggugat! (Menjawab Tulisan:

"Menggugat Ahmadiyah), 3 ed. (Bogor: Neratja Press, 2014).
} 
tetapi banyak persamaan yang cukup signifikan dengan para Nabi yang lain, dalam artian ia juga menerima wahyu. Wahyu yang diterima oleh Nabi bukanlah yang dapat berfungsi sebagai syariat meskipun banyak mengandung pengetahuan dan berita ghaib. Nabi dengan katagori ini sering juga disebut dengan Nabi bukan haqiqi. ${ }^{37}$

Menurut mereka, jenis wahyu dalam ajaran Islam cukup banyak macamnya dibagi ke dalam dua bagian, yang sama pentingnya untuk membedakan derajat kenabian, di antaranya ialah: pertama, wahyu syariat dan kedua, wahyu tanpa syariat. Wahyu syariat tidak mungkin turun lagi sesudah al-Qur'an, karena Syariat al-Qur'an sudah lengkap sampai Hari Kiamat, sedangkan wahyu tanpa syariat mungkin saja turun sewaktu-waktu. ${ }^{38}$

Selanjutnya dalam wahyu yang lain Allah SWT Berfirman:

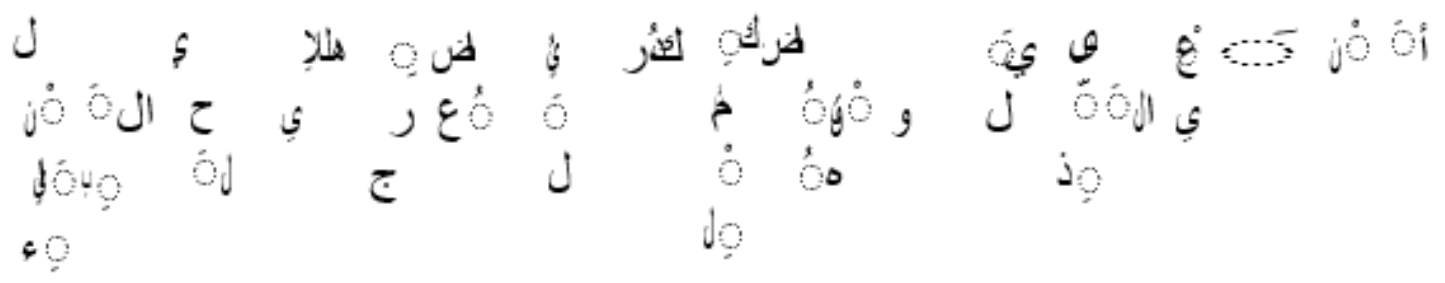

Artinya: Engkau adalah Isa, yang waktu-nya tidak disia-siakan. Misal engkau adalah mutiara yang tidak disia-siakan, pahlawan Allah di dalam jubbah para nabi. ${ }^{39}$

Tadzkirah adalah wahyu yang diturunkan kepada Mirza Ghulam di QadianIndia. ${ }^{40}$ berbunyi:

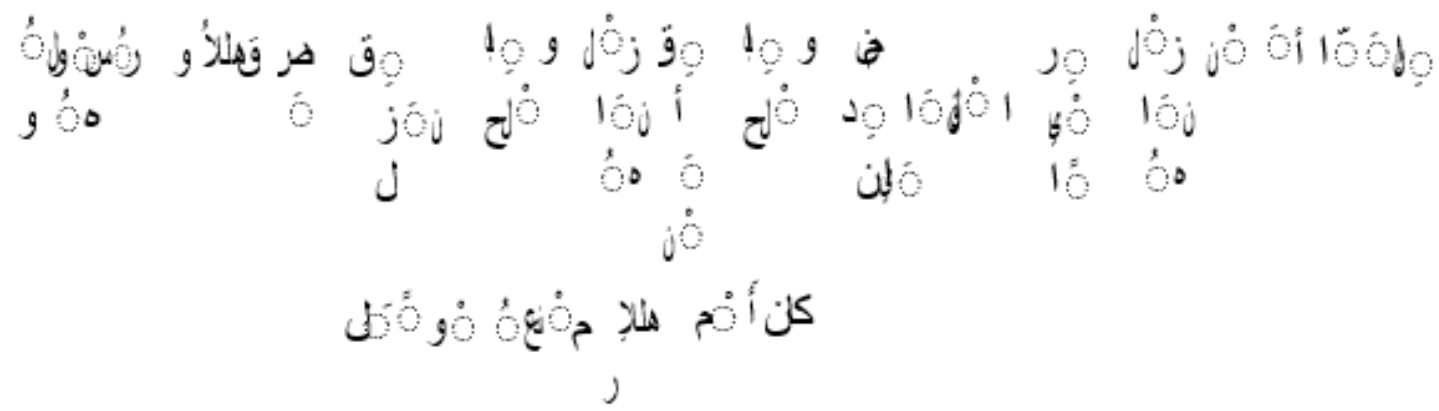

Artinya: Kami telah menurunkan dia itu di dekat Qadian dan Kami turunkan dia itu dengan benar dan dia itu turun dengan benar. Perkataan-perkataan Allah dan Rasul-Nya telah menjadi sempurna. Perintah Allah pasti harus terlaksana. ${ }^{41}$

\footnotetext{
${ }^{37}$ Susmojo Djojosugito, Hazrat Mirza Ghulam Ahmad Bukan Nabi Hakiki (Yogyakarta: PBGAI, 1984).

${ }^{38}$ Mahmud Ahmad Cheema, Tiga Masalah Penting (Jakarta: Neratja Press, 2017).

${ }^{39}$ Anjam-e-Atham (Urdu), hal. 77; Tadzkirah, hal. 288, Edisi 1969

${ }^{40}$ Ibid hlm.45

${ }^{41}$ Ibid hlm.49-50
} 
Didasarkan atas hadis:

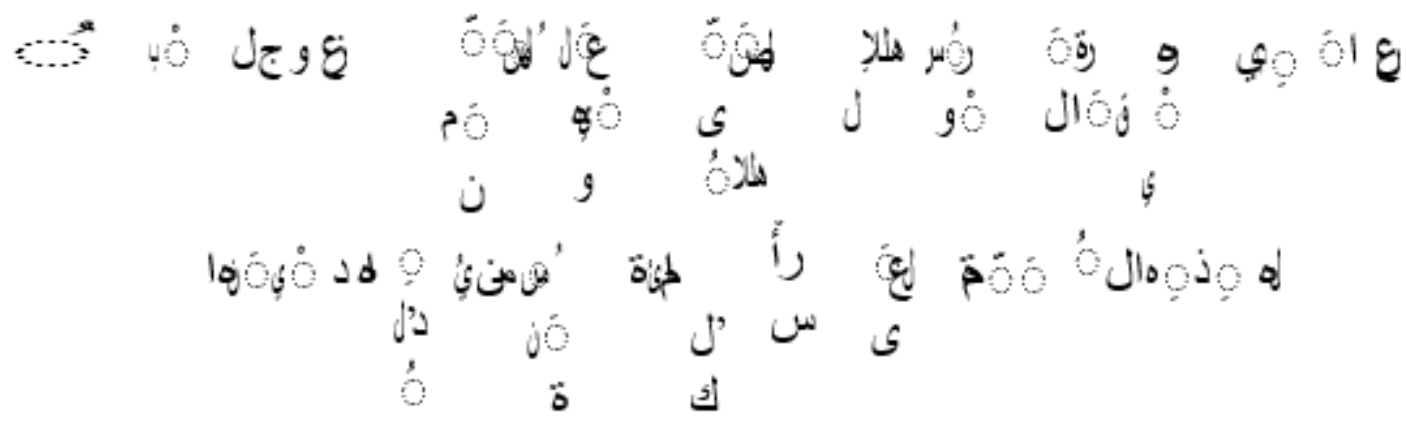

Artinya: Abu Hurairah meriwayatkan, Rasulullah SAW bersabda: Sesungguhnya Allah Yang Maha Perkasa akan mengutus di dalam umat ini (Mujaddid-mujaddid) pada setiap permulaan seratus tahun, yang akan memperbarui Agama-Nya.

Penggunaan istilah muhaddath, dalam karyanya berjudul Izala Auham, "bukan pendakwahan kenabian, melainkan pendakwahan muhaddatsiah yang telah dilakukan atas perintah Allah Ta'ala ... Hal itu dinyatakan suatu kenabian majazi atau suatu bagian yang kokoh kenabian, apakah hal itu sebagai pendakwahan kenabian ${ }^{42}$

Akan tetapi, bagi GAI sosok yang akan memperbaharui agama dalam hadis di atas, tidaklah berasal dari umat Nabi Isa a.s alasannya adalah, kalau yang akan dibangkitkan lagi adalah Nabi Isa a.s sebagaimana yang diutus Bani Israil, maka hal itu akan membuka dan mencederai segel penutup kenabian. Hal iniakan merusak aqidah umat Islam yang meyakini bahwa Nabi Muhammad saw adalah penutup para Nabi. Sementara apabila kedatangan al-Masih tersebut bukanlah Nabi berarti akan menjatuhkan derajat kenabian Nabi Isa a.s. ke dalam manusia biasa. ${ }^{43}$ Terdapat pandangan yang kurang lebih hampir sama dalam melihat kenabian dengan Qodian, bahwasanya kenabian yang sebetulnya menentukan derajat dan kedalaman revolusi kerohanian yang diadakan seorang Nabi tergantung pada posisi dan derajat Nabi, karena kekuatan rohaninya tercermin di dalamnya. Sebenarnya Nabi-Nabi itu adalah bapak revolusi dalam Islam karena Mirza Ghulam Ahmad memang menekankannya sendiri. ${ }^{44}$

\footnotetext{
${ }^{42}$ http://ahmadiyah.org/membedah-teologi-ahmadiyah-yang-digugat/, Diakses pada tanggal 8Januari 2021

${ }^{43}$ Mahally, Benarkah Ahmadiyah Sesat.

${ }^{44}$ Hadhrat Mirza Bashiruddin Mahmud Ahmad, Inqilab Haqiqi (Revolusi Sejati) (Bandung: Jemaat Ahmadiyah Indonesia, 1992).
} 
Metode GAI dalam memahami hadits tentang turunnya Al Masih (Nuzul alMasih), menurut mereka, harus dipahami secara qias, jangan dipahami secara harfiah, seperti dalam memahami hadits berikut:

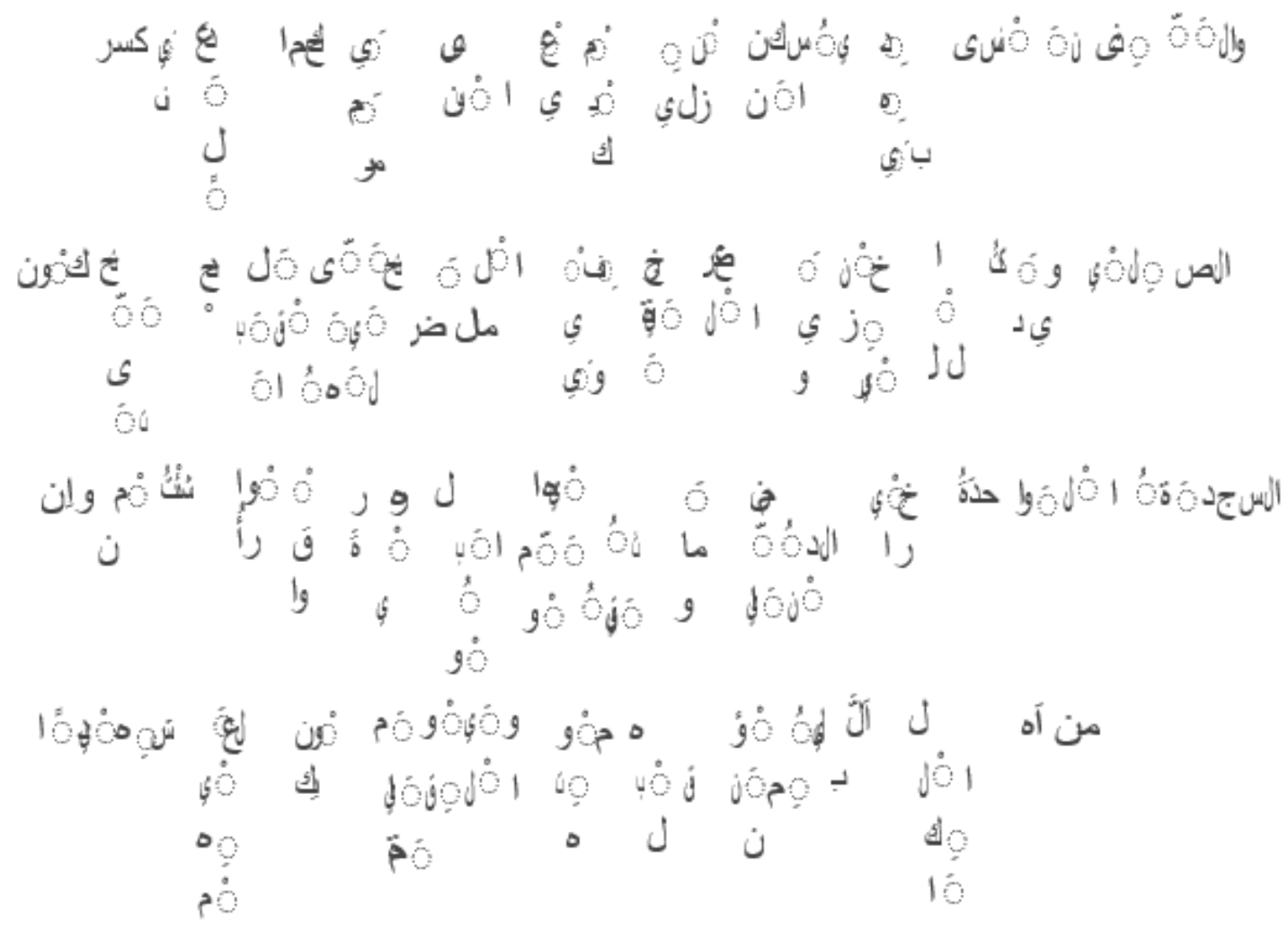

Artinya: Demi Dzat yang jiwaku berada di tangan-Nya, sungguh Isa ibnu Maryam di kalangan kamu hampir turun, sebagai hakim yang adil, lalu ia memecahkan salibdan membunuh babi, menghilangkan pajak, melimpahkan harta sehingga tiada seorang pun yang mau menerimanya, sampai-sampai satu kali sujud lebih baik daripada dunia dan semua isinya; kemudian Abu Hurairah R.A berkata: Bacalah oleh kalian jika engkau mau: 'Dan tiada seorang pun ahli kitab, kecuali ia mengimani kematian Isa di atas salib sebelum matinya ahli kitab itu dan pada hari Kiamat ia akan menjadi saksi atas mereka. ${ }^{45}$

Argumentasi yang dijadikan pegangan mereka dalam memahami hadits di atas yaitu, pertama, sabda Rasulullah saw di atas secara lahiriyah ditujukan kepada para sahabatnya, akan tetapi secara hakikat ia ditujukan kepada umat Islam akhir zaman. Kedua, Nabi Isa a.s sama sekali tidak dapat dikategorikan ke dalam kata fi kum (Umat Nabi Muhammad saw) karena beberapa hal. Antara lain, Nabi Isa a.s bukan umat Nabi Muhammad saw, Nabi Isa a.s adalah pimpinan Bani Israil, Nabi Isa a.s sudah wafat

\footnotetext{
${ }^{45}$ Al-Bukhari, Juz II, bab Nuzulu Isa ibnu Maryam, hlm.256
} 
dan orang yang sudah wafat tidak akan dibangkitkan lagi sebelum hari kiamat datang. ${ }^{46}$

Mengingat salah satu dari umat Nabi Muhammad SAW yang mempunyai perangai dan sifat seperti Nabi Isa, dalam teologi Ahmadiyah bahwa al-Masih dan alMahdi adalah satu pribadi' sehingga bagi GAI merupakan Mirza Ghulam, dipahami sebagai sosok yang berkepribadian seperti Isa a.s. yang menuntun umatnya. Oleh karena itu, bagi mereka Wahyu yang disampaikan kepada Mirza Ghulam (al-Mahdi) adalah untuk menginterpretasikan al-Qur'an sesuai dengan ide pembaharuannya. ${ }^{47} \mathrm{Di}$ samping bagi mereka kata "pembaruan", dalam konteks Mirza Ghulam, hanyalah mengembalikan Islam pada pangkal kemurniannya. ${ }^{48}$

\section{SIMPULAN}

Pandangan GAI secara umum adalah memusatkan pada pengalaman Mirza Ghulam Ahmad. Dalam dakwah Islam, keduanya sama mengikuti agenda yang telah digariskan Mirza Ghulam Ahmad. Mirza Ghulam Ahmad menurut GAI adalah bukan seorang Nabi hakiki sebagaimana halnya yang diduga kalangan non Ahmadiyah. Tetapi bagaimanapun juga, bagi GAI ia mempunyai persamaan cukup besar dengan Nabi, karena menerima wahyu, meskipun wahyu yang diterimanya tidak tasyri' dan mengandung pemberitahuan atau pengajaran tentang hal yang ghaib. Dalam hal ini, Mirza Ghulam lebih tepat disebut Muhaddath, orang yang banyak menerima firman Ilahi. Oleh karena firman Ilahi (wahyu) merupakan sebagian kenikmatan yang dianugerahkan pada Nabi, maka para muhaddath secara majazi atau kiyasan disebut Nabi majazi.

Dengan demikian, status kenabian yang dalam hal ini wahyu yang diterima Mirza Ghulam Ahmad oleh kalangan GAI menggunakan istilah Nabi ghayr mustaqill. Seperti halnya yang juga telah lumrah dikenal dalam kalangan tasawuf, pemujaan Mirza Ghulam Ahmad pada Muhammad saw, dan pemujaan pengikutnya kepada Mirza Ghulam Ahmad, seperti yang dikatakan Mircea Eliade, bahwa lambang-lambang tersebut menunjukkan ke arah kekuasaan-kekuasaan yang ada di atas dan di luar manusia (transenden). Mirza Ghulam Ahmad diposisikan sebagai Imam atau pengantara antara umat dan hakikat abadi,

\footnotetext{
${ }^{46}$ Yusuf dan Sabandi, Ahmadiyah Menggugat! (Menjawab Tulisan: "Menggugat Ahmadiyah).

${ }^{47}$ Zulkarnain, Gerakan Ahmadiyah di Indonesia.

${ }^{48}$ Barsihannor, Haruskah Membenci Ahmadiyah.
} 
sehingga umat hanya berpartisipasi melalui wakil, tidak secara langsung dalam perayaan besar seluruh umat merayakan keselamatannya secara bersama.

\section{DAFTAR PUSTAKA}

Ahmad, Hadhrat Mirza Bashiruddin Mahmud. Inqilab Haqiqi (Revolusi Sejati). Bandung: Jemaat Ahmadiyah Indonesia, 1992.

Al-Azhari, Amir Aziz. Pangkal Perpecahan Ahmadiyah. Diedit oleh Yatimin A.S. Jakarta: Darul Kutubil Islamiyah, 2016.

Barsihannor. Haruskah Membenci Ahmadiyah. Yogyakarta: Kota Kembang, 2009.

Bruinessen, Martin van. Rakyat Kecil, Islam, dan Politik. Yogyakarta: Gading, 2013.

Burhanudin, Asep. Jihad Tanpa Kekerasan. Yogyakarta: LKiS, 2005.

Cheema, Mahmud Ahmad. Tiga Masalah Penting. Jakarta: Neratja Press, 2017.

Connolly, Peter. Aneka Pendekatan Studi Agama. Diedit oleh Imam Khoiri. Yogyakarta: LKiS, 2011.

Dillistone, F. W. The Power of Symbol. Diedit oleh A. Widyamartaya. 5 ed. Yogyakarta: Kanisius, 2006.

Djamaluddin, M. Amin. Ahmadiyah dan Pembajakan Al-Qur'an. Jakarta: LIPI, 2003.

Djojosugito, Susmojo. Hazrat Mirza Ghulam Ahmad Bukan Nabi Hakiki. Yogyakarta: PBGAI, 1984.

Fadli, Adi. “Ahmadiyah: Sebuah Titik yang Diabaikan.” Ulumuna 11, no. 2 (2007): 413. Hammann, Louis J. The Ahmadiyya Movement in Islam. Diedit oleh M. A. Suryawan. Washington DC: Gettysburg College, 1985.

Jaiz, Hartono Ahmad. Aliran dan Faham Sesat di Indonesia. Jakarta: Pustaka Al-Kautsar, 2008.

Kurnia, A. Fajar. Teologi Kenabian Ahmadiyah. Jakarta: Wahana Semesta Intermedia, 2008.

Lubis, Syarif Ahmad. Jemaat Ahmadiyah: Sebuah Pengantar. Parung: JAI, 1994.

Mahally, Abdhul Halim. Benarkah Ahmadiyah Sesat. Jakarta: Cahaya Kirana Rajasa, 2006.

Majid, Nurcholis. Kontekstualisasi Doktrin Islam dalam Sejarah. Diedit oleh Budy Munawar Rahman. 2 ed. Jakarta: Paramadina, 1995.

Mudzakkir, Amin. "Minoritasi Ahmadiyah di Indonesia.” Masyarakat Indonesia: Jurnal 
Ilmu-Ilmu Sosial Indonesia 37, no. 2 (2011): 1-24.

Mulyono. "Ahmadiyah Pasca Fatwa." ahmadiyah.org, 2012. https://ahmadiyah.org/ahmadiyah-pasca-fatwa/.

Novianti, Ida. “Kenabian Mirza Ghulam Ahmad.” Purwokerto: STAIN Purwokerto Press, 2006.

Nuruddin, M Ahmad. "Falsafah Kenabian, Jemaat Ahmadiyah Indonesia.” Bogor, 1999. Riyadi, Agus. "Tarekat sebagai Organisasi Tasawuf (Melacak Peran Tarekat dalam Perkembangan Dakwah Islamiyah)." Jurnal at-Taqaddum 6, no. 2 (2014): 359-85. Suryawan, M.A. Bukan Sekedar Hitam Putih. Tangerang: Azzahra Publishing, 2006.

Sutirman, Maman, Kunto Sofianto, dan Agus Nero Sofyan. "Respons Jemaat Ahmadiyah Indonesia terhadap Fatwa Majelis Ulama Indonesia serta Kajian dari Lembaga Penelitian dan Pengkajian Islam.” Sosio Humanika 12, no. 2 (2019): 105-20.

Syaifuddin, Ahmad Fidyani. Konflik dan Integrasi Perbedaan Faham dalam Agama Islam. Jakarta: Rajawali, 1986.

Thohir, Ajid, dan Ading Kusdiana. Islam di Asia Selatan, Melacak Perkembangan Sosial, Politik Islam di India, Pakistan dan Bangladesh. Bandung: Humaniora, 2006.

Yusuf, H. R. Munirul Islam. Bantahan Lengkap (Menjawab Keberatan Atas Beberapa Wahyu di Dalam Tadzkirah) Dan Tabayyun (Penjelasan). Bogor: Bintang Grafika, 2011.

Yusuf, RH Munirul Islam, dan Ekky O. Sabandi. Ahmadiyah Menggugat! (Menjawab Tulisan: "Menggugat Ahmadiyah). 3 ed. Bogor: Neratja Press, 2014.

Zed, Medika. Metode Penelitan Kepustakaan. Jakarta: Yayasan Obor Indonesia, 2008.

Zulaiha, Eni. "Fenomena Nabi dan Kenabian dalam Perspektif AlQuran." Al Bayan: Jurnal Studi Al-Qur'an dan Tafsir 1, no. 2 (2016): 149-64.

Zulkarnain, Iskandar. Gerakan Ahmadiyah di Indonesia. Yogyakarta: LKiS, 2005. 